\title{
Predictors of Cyberbullying among Malaysian Youth
}

\author{
Akmar Hayati Ahmad Ghazali ${ }^{1,2 *}$, Asnarulkhadi Abu Samah ${ }^{1,3}$, Siti Zobidah Omar ${ }^{1,2}$, Haslinda \\ Abdullah $^{1,3}$, Aminah Ahmad ${ }^{1}$, Hayrol Azril Mohamed Shaffril ${ }^{1}$ \\ ${ }^{1}$ Institute for Social Science Studies, Universiti Putra Malaysia \\ ${ }^{2}$ Faculty of Modern Language and Communication, Universiti Putra Malaysia \\ ${ }^{3}$ Faculty of Human Ecology, Universiti Putra Malaysia
}

\begin{abstract}
Cyberbullying has emerged of late as a serious issue, especially among the most active internet users in Malaysia - youths. As the number of related studies is still lacking, the present study aims to determine the predictors of cyberbullying among youths in Malaysia. The study is quantitative in nature and in total had involved 400 youths aged between 18 to 40 years old. The findings suggest that predictors such as age, loneliness, self-esteem, and empathy yielded significant relationship with cyberbullying, while males were predominantly reported to perpetrate cyberbullying than females. Several recommendations were highlighted and hopefully, it can assist any concerned parties in developing concrete strategies to reduce cyberbullying cases among youths in Malaysia further.
\end{abstract}

Keywords: Youth; Cyberbully; Youth development

Copyright: This is an open access article distributed under the terms of the Creative Commons Attribution-NonCommercialShareAlike 4.0 International (CC BY-NC-SA 4.0) license which permits unrestricted use, distribution, and reproduction in any medium, for non-commercial purposes, provided the original work is properly cited.

\section{INTRODUCTION}

Cyberbullying can be understood as a willful act of repeated harm inflicted through the use of computers, cell phones, and other electronic devices (Cyberbullying Research Center, 2014). Understandably, cyberbullying problems usually occur among youths as they

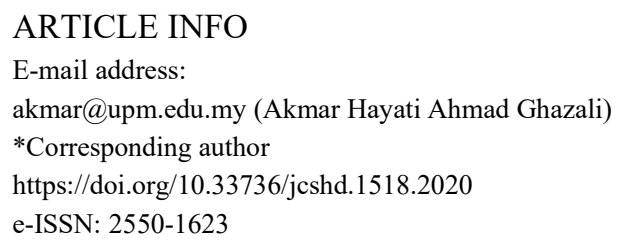

Manuscript received: 28 November 2019; Accepted: 12 December 2019; Date of publication: 31 March 2020. see it as one way to stay popular and make others see them as powerful (Duhue et al., 2008).

The definition of youth differs in each country. The United Nation (UN) for example, defines youth as those aged between 15 to 24 years old, Brazil refers to youth as those aged between 15 to 29 years old, and Vietnam refers to youth as 15 to 35 years old. In Malaysia, as defined in the Youth Development Policy in 1997, youth refers to people aged between 15 to 40 years old. Drawing on the official websites of the Institute for Youth Research Malaysia (IYRES) the total number of youths in Malaysia are approaching half of 
Akmar Hayati Ahmad Ghazali et al.

the total population (13.68 million) with 6.94 million of them are male. More than $98 \%$ of youths in Malaysia are literate and have access to high education. Expectedly, this group of people is among the most active users of the internet. The United Nations' International Telecommunication Union (ITU) via their Information Society 2013 report had ranked Malaysian youths as the fourth most active Internet users in the world. They are also active users of social media as findings by IYRES managed to prove nearly two-third $(63 \%)$ of youths in Malaysia preferred to engage in social media during their leisure time.

Youth practised cyberbully in various forms and among the common ones are giving mean or hurtful online comments, spreading rumours and posting mean or hurtful pictures (Calvete et al., 2010; Ang et al., 2010). Statistics on cyberbully across the globe demonstrates its seriousness. In a developed country such as Britain, for example, it was found that $11 \%$ of young people had experienced cyberbullying, whereas in a less developed country such as India, about $32 \%$ of young people had cyberbully experiences. In Malaysia, $25 \%$ of school students had been victims of cyber bullies, and there is a high possibility that they kept quiet and hoped that the bullying would eventually stop. The emerging issues of cyberbullying among youths has attracted scholars across the globe to examine it from various perspectives, and one of them is by looking from the psychological factors. There are various factors examined, but among the prominent ones are feeling of loneliness, self-esteem, empathy, and past experiences of being cyberbullied (EBC).

These prominent factors were rigorously examined by scholars across the globe
(Cuadrado-Gordillo and Fernandez-Antelo, 2016; Garaigordobil, 2017; Brewer and Kerslake, 2015; Sahin, 2012); however, these factors are less discussed in Malaysia. Albeit a few existing local studies, most of them focused on the effects of internet usage frequency and cyberbullying activities (Balakrishnan, 2015), and the physical bully (Wan et al., 2014; Uba et al., 2010; Yaakub et al., 2010; Mohamad Salleh and Zainal, 2014), which ensued in a paucity of studies that focuses on the effects of predictors such as loneliness, empathy, self-esteem, EBC, age, and gender on cyberbullying activities among youths. Additionally, inconsistent findings from existing studies have urged the present local study to produce a more concrete result that is fit into the local context.

\section{REVIEW OF LITERATURE}

\section{The effects of gender on cyberbullying ac- tivities}

Previous studies have confirmed that gender has an influence on cyberbullying activities as males and females were involved in cyberbullying activities in their own unique ways. Several studies found that males were more likely to engage as cyberbullies as they see it to be a strategy to become and to stay popular and to make others see them as powerful (Laftman et al., 2013; Wong et al., 2014; Kokkinos et al., 2014; Tanrikulu and Campbell, 2015; Baldry et al., 2016). Meanwhile, other studies found that females were more likely to be cyberbullies due to the indirect nature of communication (Monks et al., 2016; Festl, 2006; Keith and Martin, 2005) However, it was noted that gender has inconsistently produced an influence on cyberbullying as a number of studies have detected 
similarities instead of differences between these two groups (Beckman et al., 2013; Park et al., 2014; Balakrishnan, 2015; Calvete et al., 2010; Li, 2010)

\section{The effects of age on cyberbullying activi- ties}

There are inconsistent conclusions on the effect of age on cyberbullying. Some studies have concluded the inexistent correlation between age and cyberbullying. Such finding was concluded by Balakrishnan (2015) while others have reported a lack of correlation between age and cyberbullying (Didden et al., 2009; Varjas et al., 2009). Barlett and Chamberlin (2017) on the other hand, have concluded that age does correlate with cyberbullying by claiming that older people involved less in cyberbullying activities compared to the younger people. This result was somehow expected as people generally grow wiser and more mature with age. Additionally, Baldry et al. (2016) and Festl (2006) demonstrated a similar result and concluded that cyberbullying as an age-related issue. Contradict to findings of Barlett and Chamberlin (2017), Baldry et al. (2016), and Festl (2006), Kwan and Skoric (2013) somehow noted that the elderlies were more likely to engage in cyberbullying activities than the youngsters.

\section{The effects of empathy on cyberbullying activities}

Empathy covers the sharing and understanding of another person's emotional state (Cohen \& Strayer, 1996). Empathy was found to be a valid predictor of traditional bullying (Del Rey et al., 2016; Wong et al., 2014; Kowalski and Limber, 2013) and similar effects can be seen within the case of cyberbullying (Ang et al., 2010; Brewer and Kerslake, 2016; Wong et al., 2014; Del Rey et al., 2016; Lee and Shin, 2017). Del Rey has concluded that both cognitive and affective empathy have negatively predicted traditional bullying and cyberbully perpetration while Wong et al. (2014) have noted that people with a profound sense of empathy were more likely to cyberbully others. Ang et al. (2010) on the other hand, explained that for both boys and girls with low cognitive empathy tend to yield higher scores on cyberbullying compared to those who had higher cognitive empathy. This result was similarly found for boys with high affective empathy. Nevertheless, for girls, either with high or low levels of cognitive empathy, they still ensued in similar levels of cyberbullying.

\section{The effects of loneliness on cyberbullying activities}

Loneliness is seen as perceived social isolation and not physical separation from others (Brewer \& Kerslake, 2015). Most existing studies focus on the influence of loneliness on cyberbully victims and have concluded that the more time spent on the internet by lonely people for companionship, the more they become exposed to a number of potential risks leading to cyberbullying victimization (Yubero et al., 2016; Brighi et al., 2012; Sahin, 2012; Schoffstall \& Cohen, 2011). There are few studies that looked into the influence of loneliness on cyberbullies. Yubero et al. (2017) and Brewer and Kerlake (2016), for example, found no association between loneliness and cyberbullying activities, they claimed that future studies should explore loneliness as a predictive ability. Brewer and Kerslake (2015) urge further investigation on loneliness as lonely people tend to feel 
Akmar Hayati Ahmad Ghazali et al.

rejected and to conduct cyberbullying may represent a form of empowerment or aggression against those perceived to have rejected their advances.

\section{The effects of self-esteem on cyberbullying activities}

Self-esteem can be understood as a favourable or unfavourable attitude towards the self (Rosenberg, 1965). Self-esteem was proven to be a prominent factor for traditional bullying (Guerra et al., 2011; Gendron et al., 2011), and the same goes for the context of cyberbullying. Previous studies have confirmed the relationship between self-esteem and cyberbullying. Kowalksi and Limber (2013), and Brewer and Kerslake (2015) have both confirmed people with low self-esteem were more likely to cyberbully as they were comfortable with relative safety and anonymity of the virtual environment. Yubero et al. (2017) however, found no association between self-esteem and cyberbullying, while studies which were done by Palermiti et al. (2017), and Cenat et al. (2014) only reported connections between self-esteem and those with EBC.

\section{Past experiences of being cyberbullied (EBC)}

EBC can be a prominent predictor of cyberbullying (Balakrishnan 2015; Lee and Shin, 2017; Chapin and Coleman, 2017). Balakrishnan (2015) has concluded that cyberbully victims with EBC might not have the courage to fight back their bullies physically, but this may not be the case in the virtual world as the nature of communication is different. Lee and Shin (2017) on the other hand have stated that cyberbully victims tend to bully others in the virtual world as they seek revenge and have redirected feelings while Chapin and Coleman (2017) found that cyberbully victims admit continuing cyberbullying others and were also likely to blame victims for 'bringing it on themselves'.

\section{Present study}

There is a paucity of local studies that focuses on the effects of specific psychological factors and demographic factors on cyberbullying activities among youths, which gears this study to its primary objective - to examine the predictive abilities of loneliness, empathy, self-esteem, EBC, age, and gender on cyberbullying activities among youths in Malaysia.

In addition to this, mixed results from existing studies are prone to be solved. In the case of gender, several studies by Tanrikulu and Campbell (2015), and Baldry et al. (2016) both have concluded that males were more likely to be cyberbullied while other studies by Monks et al. (2016), and Festl (2006) have found otherwise. Within the scope of psychological factors such as self-esteem, Kowalski and Limber (2013) have noted that people with low self-esteem were more likely to cyberbully others. Comparatively, Yubero et al. (2017) found no association between selfesteem and cyberbullying.

In line with previous studies, the present study consists of prominent cyberbullying factors such as empathy, self-esteem, EBC, age, and gender. It was hypothesized that empathy, self-esteem, and age would be significantly correlated with cyberbullying activities (Kowalksi and Limber, 2013; Brewer and Kerslake, 2016) while it is predicted that 
Akmar Hayati Ahmad Ghazali et al.

within the scope of Malaysian youth, the males are more likely to be cyberbullies (Laftman et al., 2013; Wong et al., 2014; Kokkinos et al., 2014; Tanrikulu and Campbell, 2015; Baldry et al., 2016). Furthermore, another variable such as EBC is predicted to significantly correlate with cyberbullying activities (Balakrishnan 2015; Lee and Shin, 2017; Chapin and Coleman, 2017). The present study includes loneliness as one of the predictors leading to cyberbullying, although there were limited studies done to examine its effect. Brewer and Kerslake (2015) have urged further investigation on loneliness as loners tend to feel rejected and cyberbullying is seen as a form of empowerment or aggression against those whom they perceive to have rejected their advances.

\section{METHODOLOGY}

\section{Participants}

The respondents were among youth between 18-30 years old. The mean score for the respondents' age was 21 years old, and about $39.0 \%$ of them fall within the age group of 22 to 22 years old. Majority of the respondents $(66.9 \%)$ possessed a tertiary education level while nearly two-thirds of them (70.8\%) remained unemployed. More than two-thirds of the respondents $(39.8 \%)$ have between 5 to 6 household members, while most of them $(91.5 \%)$ were single. On average, the respondents have used the internet for more than 6 years and generally, they (80.5\%) have internet subscriptions. Most of the respondents surfed the internet when they were at home $(52.5 \%)$, especially during the night $(27.8 \%)$.

\section{Procedures}

A multi-stage cluster sampling was used as the main sampling technique. At the primary stage, all states in Malaysia were listed and subsequently, a state was randomly selected. Then, all districts under the selected state (Selangor) were listed, leading to four districts were randomly selected; namely, Petaling, Klang, Hulu Langat, and Sabak Bernam. At the final stage of sampling, about 100 youths aged between 18 to 30 years old were selected as respondents. Prior to the actual data collection process, the research team have established connections with authorities in the selected areas and have asked in advance for their assistance in identifying the entailed respondents. The data collection process lasted for three months (starting from January 2017 to March 2017) and took place in several places known to be futsal courts, public halls, campuses and restaurants. A number of experienced and trained enumerators were hired to assist the data collection process, using the survey as the primary data collection technique. For each survey session, an enumerator took between 20-25 minutes to complete a survey and it was conducted in the local language, which is in Malay. Whenever needed, the respondents were allowed to ask questions if they have doubts or the questions asked were vague.

\section{Measures}

The instrument was grouped into six main parts; demographic, cyberbully, their experience being cyberbullied, loneliness, self-esteem, and empathy. A pilot study was conducted to test the instrument, and as a result, all factors except for self-esteem exceeded the recommended value of .700 by Nunally (1972). To further strengthen the reliability 
Akmar Hayati Ahmad Ghazali et al.

of this instrument, items that were not clear or difficult to understand were re-phrased based on feedbacks from the enumerators and respondents. The modified instrument was then presented to two experts on technology usage, who further validated the instrument based on the content, the items, and the Likert scale.

Cyberbully - A total of 30 items was included under this section. The items were developed based on the operational definition of cyberbullying, which is an act of being wilful and execution of repeated harm inflicted through the use of computers, cell phones, and other electronic devices (Cyberbullying Research Center, 2014). The developed items were analysed using Exploratory Factor Analysis (EFA). Based on the EFA analysis, the items were pooled into four factors; namely, 1) flaming; 2) cyberstalking and harassment; 3) elimination; and 4) impersonation. After EFA, a Measurement Model was performed, and it resulted in $\chi^{2}$ $(30)=1337.71 ; \chi^{2} / \mathrm{df}=3.377 ; \mathrm{GFI}=.809$; AGFI $=.775 ; \mathrm{CFI}=.907 ; \mathrm{NFI}=.899 ; \mathrm{IFI}=$ $.907 ;$ TLI $=.898 ;$ RMSEA $=.077$. Though some of the resulted values were less than .900 as suggested by Chau (1997), Segars and Grovers (1993), Bentler (1990), Hatcher (1994), and Bentler \& Bonett (1980), nevertheless Hair et al. (2010) has recommended to refer to three to four indices in constructing a model that exceed the minimum requirement to be considered as model fit; therefore, the measurement model for the study is deemed as fit. Cyberbullying items included are such, 'Sending harassing emails or instant messages', and 'Sending instant messages or e-mails, including incorrect or bad things about others'. The reliability analysis revealed a Cronbach alpha value of .888 for this factor and it exceeds the recommended value. The respondents were given options for an answer based on a five Likert scale ranging from 0 (never) to 4 (always).

EBC - About 30 items were included under this section. The developed items referred to the respondents' experience of being cyberbullied in the past. The developed items went through an Exploratory Factor Analysis (EFA). Based on the analysis, the items were pooled into five factors; namely, 1) disturbing and embarrassing; 2) counterfeit; 3) exclusion; 4) intrusion of personal information; and 5) undesired information. The Measurement Model resulted in $\chi^{2}(30)=1161.76$; $\chi^{2} / \mathrm{df}=2.964 ; \mathrm{GFI}=.845 ; \mathrm{AGFI}=.816 ; \mathrm{CFI}$ $=.901 ; \mathrm{NFI}=.859 ; \mathrm{IFI}=.902 ; \mathrm{TLI}=.890$; RMSEA $=.070$. Though some of the resulted values are less than .900 , three to four indices in the constructed model have exceeded the minimum requirement for a model fit. The EBC items included are such, 'Harassed you sexually by cell phone or on the Internet', and 'Receiving unwanted content to my personal computer without my consent'. The pilot study also concluded that the EBC items are reliable based on its Cronbach alpha value of .753. This section measures based on a five Likert scale ranging from 0 (never) to 4 (always).

Loneliness - This section was extracted based on an established questionnaire on loneliness developed by Asher et al. (1984), which consisted of 15 items. The loneliness items included are such, 'I can find a friend when I need one', and 'There is nobody I can go to when I need help'. The pilot study concluded that loneliness yields a Cronbach alpha value of .744, demonstrating its 
Akmar Hayati Ahmad Ghazali et al.

reliability. This section measures based on a five Likert scale ranging from 0 (Not true at all) to 4 (always true).

Self-esteem - this section was extracted based on the Rosenberg Self-Esteem Scale developed by Rosenborg (1965). The self-esteem items included are such, 'I am able to do things as well as most other people', and 'I feel that I'm a person of worth, at least on an equal plane with others'. The pilot study deduced that self-esteem yields a Cronbach alpha value of .586, which did not exceed the recommended value of .700 by Nunally (1978). Hence, four items (item no 1, 3, 4 and 10) were deleted, and in turn, the Cronbach alpha value increased to .743 . This section measures based on a five Likert scale ranging from 0 (strongly agree) to 3 (strongly disagree).

Empathy -this particular section is also based on a previously developed questionnaire The Toronto empathy questionnaire by Spreng et al. (2009). The original questionnaire consisted of 16 items, which included statements such as 'Other people's misfortunes do not disturb me a great deal', and 'When a friend starts to talk about his her problems, I try to steer the conversation towards something else'. The recorded Cronbach alpha value was .795 and the respondents' answers were measured based on a five Likert scale that ranges from 0 (never) to 4 (always).

Demographic - This section covers the respondents' demographic background and internet usage patterns. Within this section, the respondents were asked questions related to their age, gender, education achievement, number of household members, possession of the internet subscription, hours spent on surfing the internet, central time for internet usage and place most likely to surf the internet. For this section, the respondents were given either an open-ended or a closed-ended option of answers.

\section{Data analytic strategy}

The final data were analysed using SPSS. For the demographic data, descriptive statistics such as frequencies, percentages, mean scores, and standard deviations were the standard procedure. Subsequently, to achieve the main objective of this study, a Pearson product-moment correlation was performed to identify any relationships that might occur between age, self-esteem, loneliness, empathy, EBC, and cyberbullying while an independent t-test was later performed to detect the differences between males and females in terms of cyberbullying.

\section{RESULTS}

Table 1 demonstrates the relationship between the five predictors and cyberbullying. All five predictors were found to yield a significant relationship with cyberbullying. EBC recorded a positive and strong relationship with cyberbullying $(r=.736, p=.0001)$ while loneliness was recorded to have a positive and moderate relationship with cyberbullying $(r=.460, p=.0001)$. Self-esteem on the other hand, recorded a positive and weak relationship with cyberbullying $(\mathrm{r}=.231, \mathrm{p}=$ .0001) while empathy also recorded a similar magnitude and direction $(\mathrm{r}=.286, \mathrm{p}=.0001)$. Another predictor, age, was found to have a negative but significant relationship with cyberbullying $(\mathrm{r}=-.119, \mathrm{p}=.0001)$. 
Akmar Hayati Ahmad Ghazali et al.

Table 1: Relationship test between predictors and cyberbullying

\begin{tabular}{lcc}
\hline Predictor & $\boldsymbol{r}$ & $\boldsymbol{p}$ \\
\hline Age & -.119 & .017 \\
EBC & .736 & .0001 \\
Loneliness & .460 & .0001 \\
Self-esteem & .231 & .0001 \\
Empathy & .286 & .0001 \\
\hline
\end{tabular}

Table 2: Comparison test on the influence of gender on cyberbully

\begin{tabular}{lcccc}
\hline & n & Mean & $\boldsymbol{t}$ & $\boldsymbol{p}$ \\
\hline & & & 4.598 & .0001 \\
Male & 199 & .67 & & \\
Female & 201 & .38 & & \\
\hline
\end{tabular}

Further analysis (see Table 2) using the independent t-test was performed to determine whether there was any difference in cyberbullying between males and females. Based on $\mathrm{t}=4.598, \mathrm{p}=.0001$, the outcome shows that there was a significant difference between males and females in cyberbullying. Findings showed that males perpetrate cyberbullying more than females.

\section{DISCUSSION}

The identified relationship between EBC and cyberbullying is consistent with past studies by Balakrishnan (2015), Lee and Shin (2017), and Chapin and Coleman (2017). A strong, positive, and significant relationship between these two variables concluded that the people who have experienced a lot of $\mathrm{EBC}$, the higher the chances of them becoming cyberbullies themselves. Several explanations would support such findings. Lee and Shin (2017) for example, have concluded that revenge was the primary motive for those who experienced EBC to cyberbully whereas Balakrishnan (2015) on the other hand, looked into the nature of communication within the virtual world where the idea of being anonymous might encourage those with EBC background to conduct cyberbully behaviours. In a study done by Chapin and Coleman (2017), they picture people with $\mathrm{EBC}$ as those who have the potential to continue cyberbullying and were also the ones likely to blame victims for "bringing it on themselves'.

Although Yubero et al. (2017) and Brewer and Kerlake (2016) failed to identify any significant association between loneliness and cyberbullying, the present study managed to contradict previous findings whereby it was found that loneliness does have a positive and significant relationship with cyberbullying. It denotes that the lonelier people feel, the more likely they are to perpetrate cyberbullying. A lonely person commonly involves themself in activities to fill their leisure time, and to surf the internet is one of them. They usually surf the internet for any companionship or building social relationships and such action might incite them to cyberbully (Brighi et al., 2012; Sahin, 2012). Furthermore, Brewer and Kerslake (2015) have confirmed that rejection might encourage loners to perpetrate cyberbully activities 
as it reflects their power or aggression against those perceived to have rejected their advances.

Albeit finding that there was a significant relationship between self-esteem and cyberbullying, which is in line with past studies, the positive relationship denotes that the higher the self-esteem, the more likely people will perpetrate cyberbullying. Such finding was found to contradict the findings of Kowalksi and Limber (2013), and Brewer and Kerslake (2015), who concluded that people with lower self-esteem were more likely to be involved in cyberbullying. Although people with low self-esteem were found to feel comfortable cyberbullying due to the relative safety and anonymity of the virtual world, youths with higher self-esteem might also be active participants of cyberbully themselves due to having high self-confidence; therefore, they face no problem in revealing their identity while cyberbullying. Nevertheless, the magnitude of the relationship was only low.

Empathy yielded a significant and positive relationship with cyberbullying. Such finding denotes that the higher the empathy, the more likely the person is to cyberbully others. Such finding is quite surprising as it not in line with previous studies by Ang et al. (2010), Brewer and Kerslake (2016), Wong et al. (2014), Del Rey et al. (2016), and Lee and Shin (2017). All of these studies found empathy to be a valid predictor for cyberbullying and established that people with low empathy were more likely to be cyberbullies.

Age was found to have a negative and significant relationship with cyberbullying. A negative relationship denotes that the older people get, the less likely they are to engage in cyberbully activities. Such finding is expected and is in line with previous studies by Barlett and Chamberlin (2017), Baldry et al. (2016), and Festl (2006). Barlett and Chamberlin (2017) claimed that compared to the younger group, the elderlies were usually more rational in making decisions before getting involved in any ruthless activities. Furthermore, ageing is usually associated with getting wiser, more mature, and thus their tendency to perpetrate cyberbullying tends to diminish with age (Balakrishnan, 2015). The recorded magnitude of this relationship was only negligible.

This study somewhat confirmed that there was a significant difference between males and females when it comes to cyberbullying. Further analysis has concluded that males tend to perpetrate cyberbullying more than females and this is in line with studies by Laftman et al. (2013); Wong et al. (2014), Kokkinos et al. (2014) Tanrikulu and Campbell (2015) and Baldry et al. (2016). The males were found to execute cyberbullying activities because they saw it as an opportunity for them to stay popular and remain dominant. Furthermore, males might engage more in cyberbullying activities due to the anonymity of the cyber world. Virtually, the males may feel less inhibited online, thus making them less fearful.

\section{LIMITATION AND FUTURE STUDIES}

The present study focuses on four districts (Petaling, Klang, Hulu Langat, and Sabak Bernam) from a selected state (Selangor) in Malaysia and the results might be more enriched if several districts from other states are included. Future research may consider 
Akmar Hayati Ahmad Ghazali et al.

including youths from Sabah and Sarawak as different cultures may offer interesting results on subject matters involving cyberbullying. Furthermore, this study required respondents to provide answers retrospectively; it may be subjected to random or inaccurate answers. This study is also prone to be limited by the respondents' social desirableness, which may affect their willingness to disclose any honest responses regarding cyberbullying, which can then affect the validity of the questionnaire. Self-report responses might lead to misinterpretation. Understandably, the respondents may misunderstand the intention of a person with whom they connect virtually, hence this may cause an over or underreporting of cyberbullying experiences. Future scholars might also be interested in objective measures and content analyses. Proactive solutions need to be taught as researchers might face challenges due to a participant's willingness to provide full access to their social media account. Furthermore, the monitoring process might stimulate a Hawthorne effect on the respondents.

\section{CONCLUSION}

Cyberbullying continues to be a significant issue among youths in Malaysia. As they represent the majority age of internet users, $25 \%$ of youths were evidently found to be cyberbullied by previous studies. Despite the urgency of this issue among youths, the paucity of local researchers and inconsistent findings from past studies has resulted in a lack of understanding of cyberbullying in Malaysia. This study managed to contribute and narrow down the gap by demonstrating the influence of several predictors on cyberbullying. The predictors are known to be ECB, loneliness, self-esteem, and empathy, recorded significant relationships with cyberbullying. Older youths, in particular, were found to engage less in virtual bullying. The study further concluded that cyberbullying perpetration and victimization among the male counterparts were more prominent than the females. The highlighted discussions may assist the concerned parties to understand the issue from multiple perspectives further. Within the Malaysian context, the proven relation between these variables contributes something new to the existing literature. Nevertheless, future studies might want to consider extending the coverage of the study area and consider objective measures and content analyses.

\section{ACKNOWLEDGEMENT}

The authors would like to thank the Ministry of Higher Education Malaysia for providing the Fundamental Research Grant Scheme for the study (Grant Number: FRGS/1/2016/ SS05/UPM/02/5)

\section{REFERENCES}

Ang, R.P., \& Goh, D.H. (2010). Cyberbullying among adolescents: The role of affective and cognitive empathy and gender. Child Psychiatry and Human Development, 41 (4), 387-397. doi: 10.1007/s10578-010-0176-3.

Asher, S.R., Hymel, S., \& Renshaw, P.D. (1984). Loneliness in children. Child Development, 55 (4), 1456-1464. doi: $10.2307 / 1130015$

Balakrishnan, V. (2015). Cyberbullying among young adults in Malaysia: The roles of gender, age and Internet frequency. Computers in Human 
Akmar Hayati Ahmad Ghazali et al.

Behavior, 46, 149-157. doi.org/10.1016/j.chb.2015.01.021

Baldry, A.C., Farrington, D.P., \& Sorrentino, A. (2016). Cyberbullying in youth: A pattern of disruptive behaviour. Psicología Educativa, 22, 19-26. doi.org/10.1016/j.pse.2016.02.001

Barlett, C.P., \& Chamberlin, K. (2017). Examining cyberbullying across the lifespan. Computers in Human Behavior, 71, 444-449.

doi.org/10.1016/j.chb.2017.02.009

Beckman, L., Hagquist, C., \& Hellstrom, L. (2013). Discrepant gender patterns for cyberbullying and traditional bullying - An analysis of Swedish adolescent data. Computers in Human Behavior, 29 (5), 1896-1903. doi.org/10.1016/j.chb.2013.03.010

Bentler, P.M., \& Bonnet, D.C. (1980). Significance tests and goodness of fit in the analysis of covariance structures. Psychological Bulletin, 88 (3), 588606.

Bentler, P.M. (1990). Comparative fit indexes in structural models. Psychological Bulletin, 107 (2), 238-46. doi: 10.1037/0033-2909.107.2.238

Brewer, G., \& Kerslake, J. (2015). Cyberbullying, self-esteem, empathy and loneliness. Computers in Human Behavior, 48, 255-260. doi.org/10.1016/j.chb.2015.01.073

Calvete, E., Orue, I., Estevez, A., Villardon, L., \& Padilla, P. (2010). Cyberbullying in adolescents: Modalities and aggressors' profile. Computers in $\mathrm{Hu}$ man Behavior, 26 (5), 1128-1135. doi.org/10.1016/j.chb.2010.03.017

Cenat, J.M., Hebert, M., Blais, M., Lavoie, F., \& Derivois, D. (2014). Cyberbullying, psychological distress and self- esteem among youth in Quebec schools. Journal of Affective Disorders, 169, 7-9. doi: 10.1016/j.jad.2014.07.019

Chapin, J., \& Coleman, G. (2017). The cycle of cyberbullying: Some experience required. Retrieved from: http://ac.elscdn.com/S0362331917300319/1-s2.0S0362331917300319main.pdf?_tid=1d139c06-605c-11e7b223-00000aab0f02\&acdnat=1499133620_6d4e79fbfd3e1096 27795f8f0cb69ffb

Chau, P. (1997). Re-examining a model for evaluating information center success using a Structural Equation Modelling approach. Decision Sciences, 28 (2), 309-334. doi.org/10.1111/j.15405915.1997.tb01313.x

Cohen, D., \& Strayer, J. (1996). Empathy in conduct-disordered and comparison youth. Developmental Psychology, 32(6), 988-998. doi.org/10.1037/0012-1649.32.6.988

Cuadrado-Gordillo, I., \& Fernández-Antelo, I. (2016). Adolescents' perception of the characterizing dimensions of cyberbullying: Differentiation between bullies' and victims' perceptions. Computers in Human Behavior, 55, 653-663. doi.org/10.1016/j.chb.2015.10.005

Cyberbullying Research Center (2014). What is cyberbullying? Retrieved from: http://cyberbullying.org/whatis-cyberbullying

Del Rey, R., Lazuras, L., Casas, J.A., Barkoukis, V., \& Tsorbatzoudis, H. (2016). Does empathy predict (cyber) bullying perpetration, and how do age, gender and nationality affect this relationship. Learning and Individual 
Akmar Hayati Ahmad Ghazali et al.

Differences, 45, 275-281. doi.org/10.1016/j.lindif.2015.11.021

Didden, R., Scholte, R.H.J., Korzilius, H., de Moor, J.M.H., Vermeulen, A., O'Reilly, M., Lang, R., \& Lancioni, G.E. (2009). Cyberbullying among students with intellectual and developmental disability in special education settings. Developmental Neurorehabilitation, 12 (3), 146-151. doi: 10.1080/17518420902971356.

Doane, A.N., Pearson, M.R., \& Kelley, M.L. (2014). Predictors of cyberbullying perpetration among college students: An application of the Theory of Reasoned Action. Computers in Human Behavior, 36, 154-162. doi.org/10.1016/j.chb.2014.03.051

Festl, R. (2016). Perpetrators on the internet: Analyzing individual and structural explanation factors of cyberbullying in the school context. Computers in $\mathrm{Hu}$ man Behavior, 59, 237-248. doi.org/10.1016/j.chb.2016.02.017

Garaigordobil, M. (2017). Conducta antisocial: conexión con bullying/cyberbullying y estrategias de resolución de conflictos. Psychosocial Intervention, 26 (1), 47-54. doi.org/10.1016/j.psi.2015.12.002

Gendron, B.P., Williams, K.R., \& Guerra, N.G. (2011). An analysis of bullying among students within schools: Estimating the effects of individual normative beliefs, self-esteem, and school climate. Journal of School Violence, 10 (2), 150-164.

doi.org/10.1080/15388220.2010.5391 66

Guerra, N.G., Williams, K.R., \& Sadek, S. (2011). Understanding bullying and victimization during childhood and adolescence: A mixed-methods study. Child Development, 82 (1), 295-310. doi: 10.1111/j.1467-8624.2010. 01556.X.

Hair, J.F., Black, W.C., Babin, B.J., \& Anderson, R.E. (2010). Multivariate data analysis. Seventh Edition. PrenticeHall, Upper Saddle River, New Jersey. Hatcher, L. (1994). A step-by-step approach to using the SAS System for factor analysis and structural equation modelling. Cary, NC: SAS Institute Inc.

Hood, M., \& Duffy, A.L. (2017). Predictors of victimisation across direct bullying, indirect bullying and cyberbullying. Retrieved from: http://ac.elscdn.com/S0191886917302556/1-s2.0S0191886917302556-

main.pdf?_tid=9390a38e-605b-11e7a6e8-00000aacb35f\&acdnat=1499133389_f2c237e958f04ea1 b888e9b7582d1c1a

Keith, S., \& Martin, M.E. (2004). Cyber-bullying: Creating a culture of respect in the cyber world. Retrieved from https://www.crisisprevention.com/Resources/Knowledge-Base/School-Bullying-Resources-and-References/Cyber-Bullying-Creating-aCulture-of-Respect-in-a

Kokkinos, C.M., Antoniadou, N., \& Markos, A. (2014). Cyber-bullying: An investigation of the psychological profile of university student participants. Journal of Applied Developmental Psychology, 35 (3), 204-214. doi.org/10.1016/j.appdev.2014.04.001

Kowalski, R.M., \& Limber, S.P. (2013). Psychological, physical and academic correlates of cyberbullying and traditional bullying. Journal of Adolescent 
Akmar Hayati Ahmad Ghazali et al.

Health, 53 (1), 13-20. doi: Palermiti, A.L., Servidio, R., Bartolo, M.G., 10.1016/j.jadohealth.2012.09.018.

Laftman, S.B., Modin, B. \& Ostberg, V. (2013). Cyberbullying and subjective health: A large-scale study of students in Stockholm, Sweden. Children and Youth Services Review, 35, 112-119. doi.org/10.1016/j.childyouth.2012.10. 020

Larranaga, E., Yubero, S., Ovejero, A., \& Navarro, R. (2016). Loneliness, parent-child communication and cyberbullying victimization among Spanish youths. Computers in Human Behavior, $65,1-8$. doi.org/10.1016/j.chb.2016.08.015

Lee, C., \& Shin, N. (2017). Prevalence of cyberbullying and predictors of cyberbullying perpetration among Korean adolescents. Computers in Human Behavior, 68, 352-358. doi.org/10.1016/j.chb.2016.11.047

Li (2010). Cyberbullying in high schools: A study of students' behaviors and beliefs about this phenomenon. Journal of Aggression, Maltreatment \& Trauma, 4, 372-392. doi.org/10.1080/10926771003788979

Mohamad Salleh, N., \& Zainal, K. (2014). Bullying among secondary school students in Malaysia: A case study. International Education Studies, 7(13), 184-191. doi: 10.5539/ies.v7n13p184

Monks, C.P., Mahdavi, J., \& Rix, K. (2016). The emergence of cyberbullying in childhood: Parent and teacher perspectives. Psicología Educativa, 22(1), 39-48.

doi.org/10.1016/j.pse.2016.02.002

Nunnally, J.C (1978). Psychometric theory. 2nd Edition. Mc-Graw Hill, New York. $\&$ Costabile, A. (2017). Cyberbullying and self-esteem: An Italian study. Computers in Human Behavior, 69, 136-141. doi.org/10.1016/j.chb.2016.12.026

Park, S., Na, E., \& Kim, E. (2014). The relationship between online activities, netiquette and cyberbullying. Children and Youth Services Review, 42, 74-81. doi.org/10.1016/j.childyouth.2014.04. 002

Rosenberg, M. (1965). The measurement of self-esteem. Society and the Adolescent Self-Image, 297 (1965), p. V307.

Sahin, M. (2012). The relationship between the cyberbullying/cyber victimization and loneliness among adolescents. Children and Youth Services Review, 34(4), 834-837. doi.org/10.1016/j.childyouth.2012.01. 010

Schoffstall, C.L., \& Cohen, R. (2011). Cyber aggression: The relation between online offenders and offline social competence. Social Development, 20 (3), 587-604. doi.org/10.1111/j.14679507.2011.00609.x

Segars, A.H., \& Grover, V. (1993). Re-examining perceived ease of use and usefulness: a confirmatory factor analysis. MIS Quarterly 17 (4), 517-525. doi:10.2307/249590

Spreng, M.C. KcKinnon, R.A., \& Levine, M.B. (2009). The Toronto empathy questionnaire: Scale development and initial validation of a factor-analytic solution to multiple empathy measures. Journal of Personality Assessment, 91, 62-71. doi: $10.1080 / 00223890802484381$. 
Akmar Hayati Ahmad Ghazali et al.

Tanrikulu, I. \& Campbell, M. (2015). Correlates of traditional bullying and cyberbullying perpetration among Australian students. Children and Youth Services Review, 55, 138-146.

doi.org/10.1016/j.childyouth.2015.06. 001

Uba, I.U. Yaacob, S.N., \& Juhari, R. (2010). Bullying and its' relationship with depression among teenagers. Journal of Psychology, 1, 15-22.

doi.org/10.1080/09764224.2010.1188 5441

Varjas, K., Henrich, C.C., Meyers, J. (2009). Urban middle school students' perceptions of bullying, cyberbullying, and school safety. Journal of School Violence, 8 (2), 159-176.

doi.org/10.1080/15388220802074165

Wan, S.W.I., Nik, R.N.J., Hatta, S. Marhani, M. \& Shamsul, A.S. (2014). Why do young adolescents bully? Experience in Malaysian schools. Comprehensive Psychiatry, 55, 114-120. doi.org/10.1016/j.comppsych.2013.05 .002

Wong, D.S.W., Chan, H.C., \& Cheng, C.H.K. (2014). Cyberbullying perpetration and victimization among adolescents in Hong Kong. Children and Youth Services Review, 36, 133-140. doi.org/10.1016/j.childyouth.2013.11. 006

Yaakub, N.F. Haron, F. Goh. C.L. (2010). Examining the efficacy of the Olweus prevention programme in reducing bullying: The Malaysian experience - Procedia: Social and Behavioral Sciences, 5, 595-598. doi.org/10.1016/j.sbspro.2010.07.148

Yubero, S., Navarro, R., Elche, M., Larranaga, E., \& Ovejero, A. (2017). Cyberbullying victimization in higher education: An exploratory analysis of its association with social and emotional factors among Spanish students. Computers in Human Behavior, 75, 439-449.

doi.org/10.1016/j.chb.2017.05.037 